\title{
Anthropometric correlates of blood pressure in hypertensive subjects in Lahore, Pakistan
}

\author{
Saima Sharif ${ }^{\text {, Abdul Majeed Cheema }}{ }^{2}$, Muhammad Naeem Khan ${ }^{3}$ \\ ${ }^{1}$ Assistant Professor, Zoology Department, Lahore College for Women University, Lahore; ${ }^{2}$ Abdul Majeed Cheema, Professor, \\ Aimed Research Institute, Lahore; ${ }^{3}$ Muhammad Naeem Khan, Professor, Department of Zoology, Quaid-e-Azam Campus, \\ University of the Punjab Lahore, Pakistan.
}

\begin{abstract}
The aim of this study is to determine correlations among anthropometric parameters, systolic and diastolic blood pressure in hypertensive subjects in Lahore, Pakistan. A total number of 510 subjects (204 males and 306 females) of age between $25-87 y$ were included in the study. The subjects were divided into pre $(n=139)$, stage 1 ( $n=193)$ and stage 2 of hypertension $(\mathrm{n}=178)$ following JNC VII criteria (2003). Following the World Health Organization (WHO) cutoffs for Asians, about $13.7 \%$ of our sample population was found to be overweight and $76.7 \%$ was obese, $54.1 \%$ had waist to hip ratio (WHR) greater than 1. It was found that females develop hypertension in earlier age than males. Body Mass Index (BMI) was greater in females while WHR in males. No significant difference was observed in BMI and WHR among the prehypertension (preHTN), stage 1 and stage 2 subjects. A significant association was found between systolic blood pressure (SBP) and WHR in pre-hypertensive subjects ( $\mathrm{r}=0.168)$. A positive significant correlation of diastolic blood pressure (DBP) was found with WHR $(\mathrm{r}=0.212)$ and $\mathrm{BMI}(\mathrm{r}=0.17)$ in prehypertensive stage. In multiple regression analysis when SBP was a dependent variable, age and BMI was determinant in preHTN, while only age was in stage 2 . When DBP was a dependent variable, WHR was predictor in preHTN and age in stage 2.
\end{abstract}

Keywords: Anthropometric parameters, BMI, WHR, Prehypertension, Pakistan.

\section{Introduction}

Hypertension (HTN) is likely the most common cardiovascular disease on earth. ${ }^{1}$ During the last decade most developing countries have experienced the emerging epidemic of cardiovascular disease ${ }^{2,3}$ with hypertension as the commonest condition, especially among urban dwellers. ${ }^{4}$ The World Health Organization (WHO) reports that the number of people with hypertension worldwide is estimated as 600 million, while 3 million die annually as a result of hypertension. ${ }^{5}$ There are well recognized ethnic and gender differences in the prevalence of hypertension. Hypertension is two times more prevalent in blacks versus white, higher in men versus women until after menopause and is typically related to many dietary factors. ${ }^{6}$ In Pakistan, HTN affects one out of every three persons over 45 year of age. ${ }^{7}$ The National Health Survey of Pakistan reported that $21.5 \%$ of the urban population over 15 years (one in every three persons the over age of 45) suffers from hypertension and only less than $3 \%$ of the hypertensive had their blood pressure (BP) controlled to the conventional recommendations of under $140 / 90 \mathrm{mmHg}$.

Obesity and hypertension are two major inter-related cardiovascular risk factors. Decrease in adiposity is one of the most effective preventive measures not only in decreasing the overall cardiovascular risk but also the BP. ${ }^{8}$ Various measures of obesity including body mass index (BMI), waist circumference (WC), waist to hip ratio (WHR) and waist to height ratio have been employed to capture the obesity related cardiovascular risk. Waist-to-

\section{Practice Points}

- Hypertension is likely the most common cardiovascular disease on earth.

- The study was conducted on prehypertensive subjects in Lahore which have not been reported earlier.

- About $57 \%$ hypertensive subjects were in the age range 40-59 years with males preponderance of $62.6 \%$.

- Higher BMI was observed in females as compare to males.

- Significant co-relation of SBP and DBP with WHR was present in prehypertensive subjects.

hip ratio and waist-to height ratio are also simple anthropometric parameters and are sometimes used as markers for abdominal adiposity. ${ }^{9}$ Obesity and hypertension are known to increase in parallel in both developed and developing countries. ${ }^{10}$ Furthermore, obesity is a major independent risk factor for the development of hypertension, type 2 diabetes, and dyslipidemia. ${ }^{11}$ Globalization, increasing urbanization, changes in traditional family structure, lifestyle and a more mechanized workplace directly affects dietary and physical activity patterns and ultimately increase the risk of such diseases. In developing countries like Pakistan, the

Correspondence: Dr. Saima Sharif, Assistant Professor, Lahore College for Women University, Lahore, Pakistan.E-mail: ssharif1978@yahoo.com. 
magnitude of uncontrolled hypertension is even greater. The aim of the present study was to determine the correlation of blood pressure with BMI and WHR in preHTN and hypertensive subjects visiting hospitals in Lahore, Pakistan.

\section{Materials and methods}

A total of 510 subjects of either sex were screened during a cross-sectional study performed from December 2005 to May 2007 at Amin Hayat memorial Trust for Diabetes and Hypertension and Punjab Institute of Cardiology (PIC), Lahore. Their demographic data, medical history, family history of hypertension and duration of the disease were recorded through a comprehensively designed questionnaire. The study was approved by the ethical committee of hospital.

Waist was measured horizontally at the level just above the uppermost border of the iliac crest. The measurement was made at a normal minimal respiration. ${ }^{12}$ Hip was measured as the maximum circumference over the buttocks. ${ }^{13}$ Central obesity was calculated by dividing the waist measurement over the hip measurement and defined as waist to hip ratio (WHR). Height was taken using standard apparatus with the subjects wearing light clothing and without shoes. Weight was measured in the upright position with a weighting scale to the nearest 0.01 kilogram $(\mathrm{kg})$. Height was measured to the nearest $0.1 \mathrm{~cm}$ by using a non-stretching tape. Obesity index or BMI was calculated as weight $(\mathrm{kg})$ divided by height squared $\left(\mathrm{m}^{2}\right)$ to estimate overall body fat distribution. ${ }^{14}$

Blood pressure was measured, using the standard mercury sphygmomanometer, on the right arm with the subject in the upright sitting position, following at least 5 minute rest. The screened subjects were categorized into the groups using the criteria of JNC VII ${ }^{15}$ : prehypertensive if systolic blood pressure (SBP) was 120-139 $\mathrm{mmHg}$ and diastolic blood pressure (DBP) was 80-89
$\mathrm{mmHg}$, stage 1 of hypertension if SBP was 140-159 $\mathrm{mmHg}$ and DBP was $90-99 \mathrm{mmHg}$, and stage 2 of hypertension if SBP was $\geq 160 \mathrm{mmHg}$ and DBP was $\geq 100$ mmHg. Overweight and obesity was defined according to Asian criteria ${ }^{9}$ and BMI greater than 23 was considered as overweight and BMI greater than 25 was considered obese. Participants who reported smoking at least 3 cigarettes per day during the previous year were classified as current smokers. Physical activity was defined as sedentary, no extra physical activity apart from activities of daily living, or physically active, if they do brisk walking at least half an hour for three days in a week.

\section{Statistical Analysis}

Statistical analysis was performed using the SPSS (version 13.0) software. All results are expressed as Mean \pm SEM. Spearman correlation was used to find the correlation and analysis of variance (ANOVA) was applied to find the significance between the studied groups. Stepwise multiple regressions were employed to study the joint effect of variables on the systolic and diastolic blood pressure.

\section{Result}

A total of 510 subjects males 206 (40.4\%), females 304 $(59.6 \%)$ of age between $(25-87 y)$ with hypertension were included in this study. The subjects were classified into preHTN $(\mathrm{n}=139)$, stage $1 \quad(\mathrm{n}=193)$ and stage 2 $(n=178)$ on the basis of BP status. The distribution pattern of the population in various categories of risk factors is given in Table 1.The highest proportion of the HTN at $56.5 \%(n=288)$ was found in the age range of 40-59 years. Prevalence of central obesity was more in males as compared to females $(65.04 \%$ vs $46.7 \%)$. Using the cut-off values of BMI, 76.7\% $(n=391)$ of the subjects were obese. Females $(82.2 \%)$ were more obese than males $(68.4 \%)$. The distribution of preHTN, stage 1 and stage 2 subjects according to the risk factors were also presented in Table 1.

Table 1: Demographic characteristics of study population

\begin{tabular}{|l|c|c|c|c|c|c|}
\hline Variables & All & Male & Female & PreHTN & Stage 1 & Stage 2 \\
\hline $\mathrm{n}$ & $510(\%)$ & $206(\%)$ & $304(\%)$ & $139(\%)$ & $193(\%)$ & $178(\%)$ \\
\hline Age (years) & $114(22.4)$ & $23(11.2)$ & $91(29.9)$ & $29(20.9)$ & $21(10.9)$ & $33(18.5)$ \\
\hline$<40$ & $288(56.5)$ & $129(62.6)$ & $159(52.3)$ & $103(74.1)$ & $129(66.8)$ & $87(48.9)$ \\
\hline $40-59$ & $108(21.3)$ & $54(26.2)$ & $54(17.8)$ & $07(5.0)$ & $43(22.3)$ & $58(32.6)$ \\
\hline$>60$ & $234(45.9)$ & $72(34.9)$ & $162(53.3)$ & $69(49.6)$ & $85(44.0)$ & $81(45.5)$ \\
\hline WHR & $276(54.1)$ & $134(65.0)$ & $142(46.7)$ & $70(50.4)$ & $108(55.9)$ & $97(54.5)$ \\
\hline$<1$ & $49(9.6)$ & $29(14.0)$ & $20(6.5)$ & $11(7.9)$ & $21(10.9)$ & $23(12.9)$ \\
\hline$>1$ & $70(13.7)$ & $36(17.5)$ & $34(11.2)$ & $14(10.0)$ & $11(5.7)$ & $24(13.5)$ \\
\hline BMI (kg/m2] & $291(76.7)$ & $141(68.4)$ & $250(82.2)$ & $114(82.0)$ & $161(83.4)$ & $131(73.6)$ \\
\hline Normal weight & $131(25.7)$ & $123(59.7)$ & $8(2.6)$ & $36(25.8)$ & $52(26.9)$ & $43(24.1)$ \\
\hline Over weight & $153(30)$ & $60(29.1)$ & $93(30.6)$ & $41(29.5)$ & $55(28.5)$ & $57(32.0)$ \\
\hline Obese & $302(59.2)$ & $115(55)$ & $187(61.5)$ & $75(53.9)$ & $121(62.6)$ & $106(59.5)$ \\
\hline Habits
\end{tabular}

South East Asia Journal of Public Health 2012;2(2):22-27. 
The mean values of age, WHR, BMI, SBP and DBP are presented in Table 2. Non-significant difference was observed among the different HTN categories in WHR and BMI while significant differences were observed in age, SBP and DBP. When the data was analyzed on the basis of gender, significant difference was observed in age, WHR, BMI and SBP.

Table 2: Study population in relation to gender and HTN categories

\begin{tabular}{|c|c|c|c|c|c|c|}
\hline $\begin{array}{l}\stackrel{0}{\Xi} \\
\frac{\pi}{J} \\
\frac{1}{2}\end{array}$ & $\begin{array}{l}\ll \\
2 \\
0 \\
z\end{array}$ & $\begin{array}{l}* \\
8 \\
0 \\
0\end{array}$ & $\frac{\infty}{0}$ & $\begin{array}{l}n \\
n \\
\infty \\
0 \\
0\end{array}$ & $\begin{array}{l}* \\
* \\
0 \\
0 \\
0 \\
0\end{array}$ & 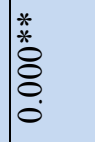 \\
\hline 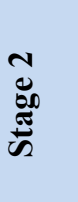 & $\stackrel{\infty}{\beth}$ & 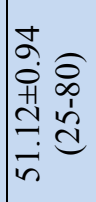 & 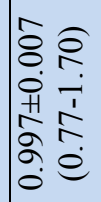 & 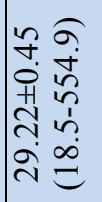 & 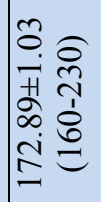 & 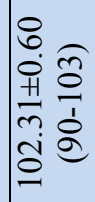 \\
\hline 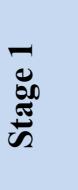 & $\hat{\sigma}$ & 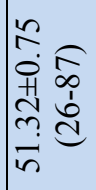 & 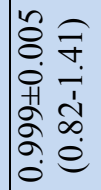 & 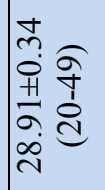 & 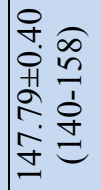 & 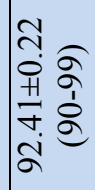 \\
\hline Z & ભે & 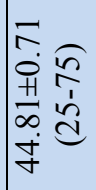 & 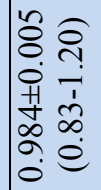 & 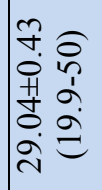 & 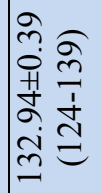 & 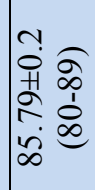 \\
\hline 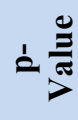 & 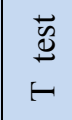 & $\stackrel{*}{*}$ & $\frac{*}{0}$ & $\begin{array}{l}* \\
\stackrel{*}{0} \\
0\end{array}$ & 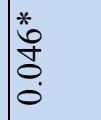 & $\frac{n}{0}$ \\
\hline ఏ્త & ঠ্ঠ & 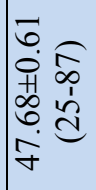 & 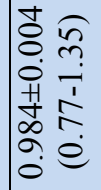 & 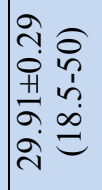 & 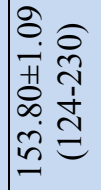 & 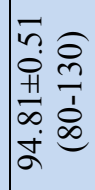 \\
\hline$\frac{\frac{0}{\pi}}{\sum}$ & ๖̊ & 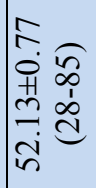 & $\begin{array}{ll}n & 0 \\
0 & 0 \\
0 & 1 \\
0 & 1 \\
1 & \infty \\
0 & \infty \\
& 0\end{array}$ & 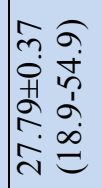 & 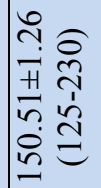 & 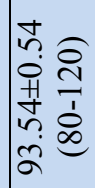 \\
\hline$\sum$ & $\frac{0}{n}$ & 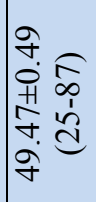 & 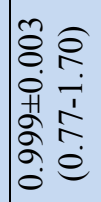 & 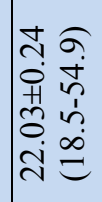 & 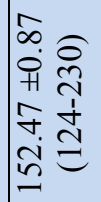 & 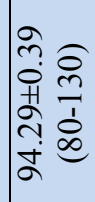 \\
\hline 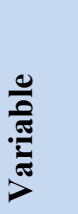 & $=$ & 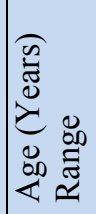 & 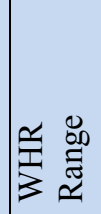 & 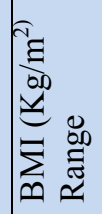 & 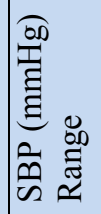 & 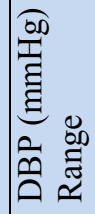 \\
\hline
\end{tabular}

Correlation analysis revealed that SBP had a significant positive correlation with age in preHTN $(r=0.239)$ and in stage $2(\mathrm{r}=0.193)$ while no association was observed in stage $1(\mathrm{r}=-0.061)$. A significant correlation of SBP and WHR was found in preHTN $(\mathrm{r}=0.168)$, while nonsignificant in other groups i.e., stage $1(\mathrm{r}=-0.024)$ and stage $2(\mathrm{r}=-0.072)$ (Figure 1).

A significant correlation was observed between DBP and age in preHTN $(r=0.176)$ and stage $2(r=0.159)$. A significant positive correlation between DBP and WHR was found in prehypertensive group $(\mathrm{r}=0.212)$ (Figure $2)$ while no association was seen in stage $1(\mathrm{r}=0.060)$ and stage $2(\mathrm{r}=-0.029)$.

A positive significant correlation was observed between DBP and BMI in prehypertensive group $(r=0.17)$, while non-significant association was found in stage $1(\mathrm{r}=$ $0.057)$ and stage $2(\mathrm{r}=0.100)$ (Figure 3$)$.

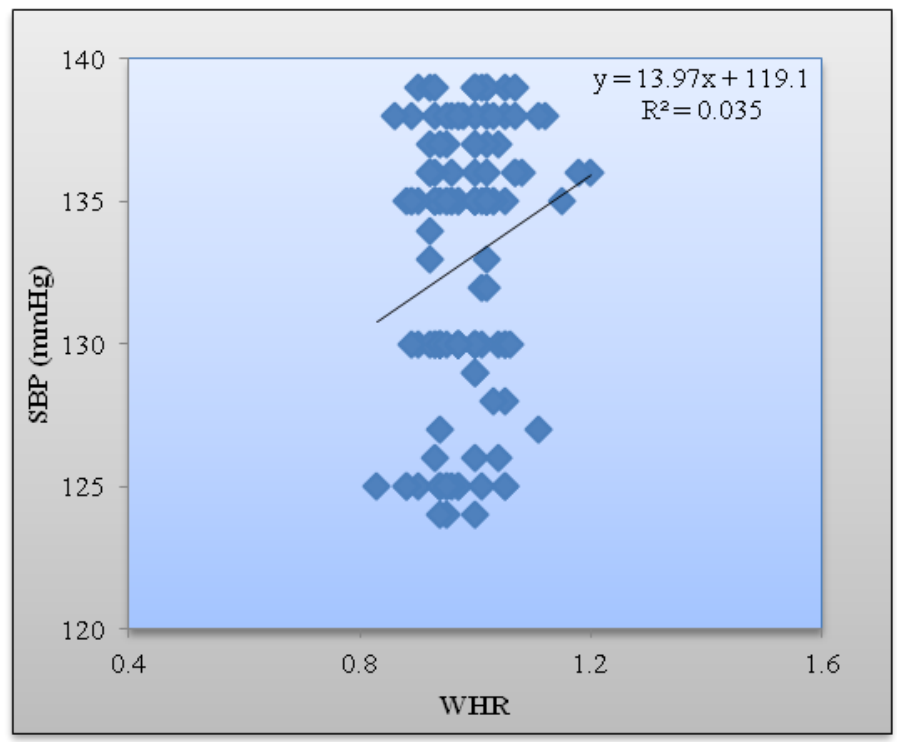

Figure 1: Significant relationship between SBP (mmHg) and WHR in PreHTN subjects

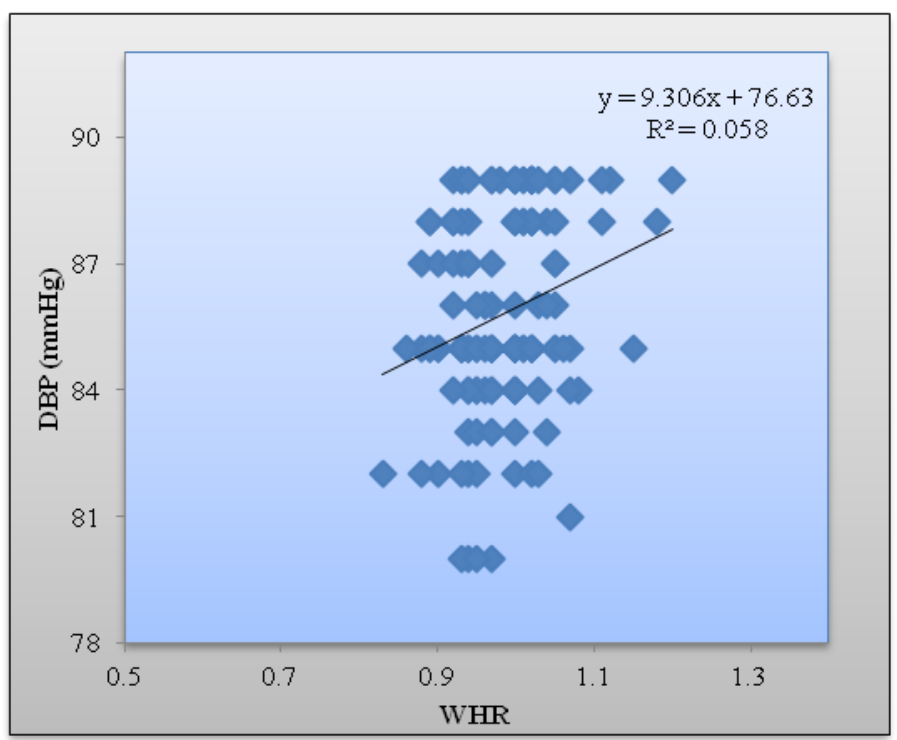

Figure 2: Significant relationship between DBP (mmHg) and WHR in PreHTN subjects 


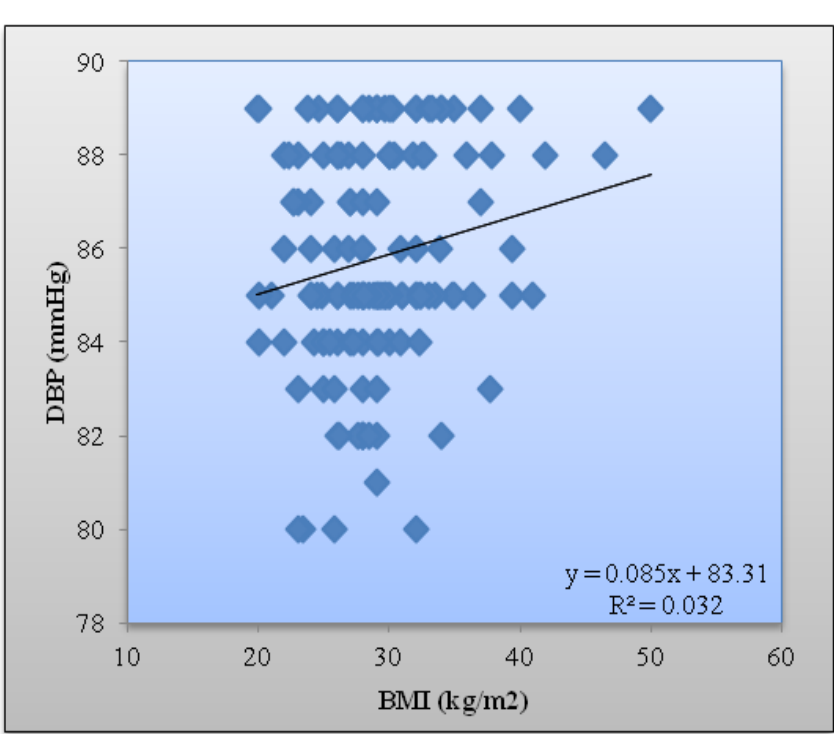

Figure 3: Study population in relation to gender and HTN categories

A significant correlation was observed in WHR with age in all three categories i.e. prehypertensive $(\mathrm{r}=$ $0.279)$ stage $1(\mathrm{r}=0.192)$ and stage $2(\mathrm{r}=0.324)$. BMI had shown an inverse significant correlation with age in stage 1 subjects $(r=-0.257)$, which indicates that with the increase of age the BMI decreases (Figure 4). The same pattern was observed in preHTN $(\mathrm{r}=-0.162)$ and stage $2(\mathrm{r}=-0.111)$ but not significant.

When stepwise multiple regression was employed considering SBP as a dependent variable, in preHTN, 2 models were computed showing age and WHR as

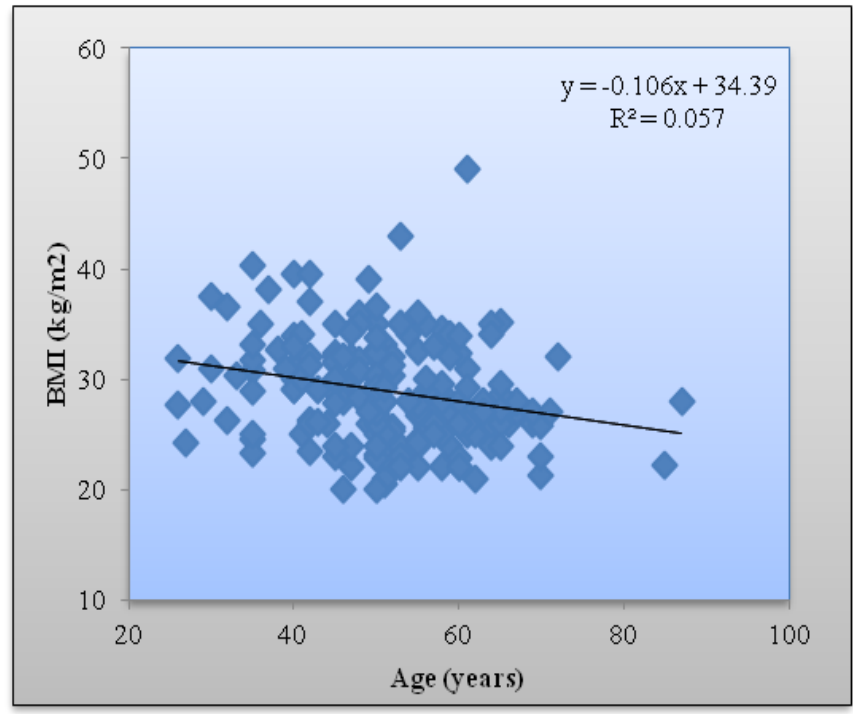

Figure 4: Significant inverse relationship between age (years) and BMI $\left(\mathrm{Kg} / \mathrm{m}^{2}\right)$ in Stage 1 hypertensive subjects

important determinants. Age is the only determinant in stage 2 while no determinant was found in stage 1 . In another stepwise multiple regressions analysis considering DBP as a dependent variable and age WHR and BMI was independent variable. WHR was the determinant in preHTN and in stage 2 age was determinant while no model was computed in stage 1 (Table 3 ).

\section{Discussion}

Despite the worldwide attention paid to the importance of hypertension and its associated complications, the disease is not adequately controlled. ${ }^{16}$ Thus it is

Table 3: Multiple regression analysis with SBP and DBP in PreHTN, Stage 1 and Stage 2 subjects

\begin{tabular}{|c|c|c|c|c|c|}
\hline \multirow[t]{2}{*}{ Model } & \multicolumn{2}{|c|}{ Unstandardized coefficients } & \multirow{2}{*}{$\begin{array}{c}\text { Standadized } \\
\text { coefficient }\end{array}$} & \multirow[t]{2}{*}{$\mathbf{T}$} & \multirow[t]{2}{*}{$p$-value } \\
\hline & B & Std.Error & & & \\
\hline \multicolumn{6}{|c|}{ Systolic blood pressure } \\
\hline \multicolumn{6}{|c|}{ PreHTN group } \\
\hline $1 \quad$ [Constant ] & 127.383 & 2.084 & & 61.121 & 0.00 \\
\hline Age & $0 / 124$ & 0.046 & 0.226 & 2.713 & 0.00 \\
\hline $\begin{array}{ll}2 & \text { [Constant ] }\end{array}$ & 122.156 & 3.262 & & 37.453 & 0.00 \\
\hline Age & 0.139 & 0.046 & 0.253 & 3.037 & 0.003 \\
\hline WHR & 0.157 & 0.076 & 0.172 & 2.067 & 0.041 \\
\hline \multicolumn{6}{|l|}{ Stage 1} \\
\hline & \multicolumn{2}{|c|}{ No model was computed } & & & \\
\hline \multicolumn{6}{|l|}{ Stage 2} \\
\hline $1 \quad$ [Constant ] & 162.691 & 4.287 & & 37.952 & 0.00 \\
\hline Age & 0.199 & 0.081 & 0.182 & 2.449 & 0.015 \\
\hline \multicolumn{6}{|c|}{ Diastolic blood pressure } \\
\hline \multicolumn{6}{|c|}{ PreHTN group } \\
\hline $1 \quad$ [Constant ] & 76.634 & 3.157 & & 24.277 & 0.000 \\
\hline WHR & 9.306 & 3.202 & 0.241 & 2.907 & 0.004 \\
\hline \multicolumn{6}{|l|}{ Stage 1} \\
\hline & \multicolumn{2}{|c|}{ No model was computed } & & & \\
\hline \multicolumn{6}{|l|}{ Stage 2} \\
\hline $1 \quad$ [Constant ] & 108.129 & 2.513 & & 61.121 & 0.000 \\
\hline Age & 0.124 & 0.046 & -0.177 & -2.382 & 0.018 \\
\hline
\end{tabular}

South East Asia Journal of Public Health 2012;2(2):22-27. 
imperative to study the hypertension in diverse populations with varied lifestyle.

In the present study a total of 510 hypertensive subjects were recruited from the hospitals. It was observed that among the selected group $70 \%$ subjects were unaware of their hypertensive status. Hypertension generally, is usually asymptomatic and only detected during routine physical examination as evident in our study. This is important because it verifies a usual understanding in Pakistan that the reason for complications related to this disorder are due to late diagnosis of the problem and hence enhancement of disease symptoms due to no proper treatment or life style modifications. It was also reported in a study ${ }^{17}$ in USA that out of 50 million adult hypertensive individuals $30 \%$ are unaware of their high BP.

Demographic data of the study population revealed that in all the categories of HTN, female subjects were younger in age as compared to males; thus females are affected by the disease comparatively at an earlier age than males. Sedentary lifestyle and significantly higher BMI and SBP in females as compared to males predisposed them to hypertension at an early stage and most of the females use contraceptive pills which was also another reason to develop hypertension in early age. In our study a greater proportion of females below 40 years of age were hypertensive as compared to males. This is in contrast with other studies which reported that males develop hypertension earlier than females. ${ }^{18}$

Majority of the study subjects were in age ranged between 40 to 59 years, with males accounting for $62.6 \%$ in this category. Age is strongly associated with hypertension as shown in several studies, where it has been reported that the prevalence of HT increased with age. ${ }^{19}$, 20

According to the WHO Consultation on Obesity, the incidence of obesity has been increasing rapidly since $1990 .{ }^{21}$ The prevalence of obesity is increasing in many developed countries ${ }^{22}$ and in many developing countries. $^{23,24}$ Overweight or obesity has been associated with high blood pressure. ${ }^{11}$ In the present study, $76.7 \%$ of the hypertensive subjects had been assessed obese which clearly strengthen the evidence that obesity is an established risk factor for hypertension. Physical inactivity is known contributing factor to the problem of obesity and hypertension and this sedentary lifestyle was seen in $70 \%$ of our studied population.

It has been observed in the study that in hypertensive subjects, WHR and BMI were same in different hypertensive categories expounding that central obesity and BMI are important contributors towards the development of HTN.

It was found that female subjects have higher BMI and male subjects have higher WHR which shows that females have more generalized while males have more abdominal obesity. Similar results were reported in another study ${ }^{25,26}$, where BMI is greater in females as com- pared to males. The gender variation may be because the pattern of fat distribution differs between men and women, with visceral fat being predominant in men and subcutaneous fat predominant in females. ${ }^{27}$

There is a general agreement that BP rises with advancing age, but the magnitude of this rise is uncertain because hypertension is a common disease and its incidences increases with rising age. ${ }^{28}$ In our study, significant positive association was found between SBP and DBP with age in preHTN and stage 2 groups but a weak association was observed in stage 1. BMI had shown an inverse relation with age because in old age the weight decreases due to which BMI also decreases.

Multiple regression analysis further elaborated that age was determinant of systolic and diastolic blood pressure in stage 2 of hypertension. However, in another study no significant association was found between hypertension and age. ${ }^{29}$

In preHTN subjects $\mathrm{SBP}$ is found to be significantly associated with WHR, reflecting that WHR causes the rise in SBP only in prehypertensive subjects. DBP also showed the positive association with WHR and BMI. It had been reported earlier that mean WHR had a significant correlation with both systolic and diastolic blood pressure in all the groups of hypertension. ${ }^{30} \mathrm{~A}$ study on workers of Vitana factory reported a significant association of SBP with BMI. ${ }^{31}$ Causal association between BMI increase and BP increase was also reported in $2000 .^{32}$

\section{Conclusion}

It has been concluded from our study that prehypertension stage is prevalent in young population. Age and WHR are important predictors of systolic and diastolic blood pressure. Furthermore, the abdominal obesity is more common $(65 \%)$ in men than women $(47 \%)$. Hypertension is major health problem and obesity has been seen as a prime risk factor for this.

\section{Acknowledgement}

The authors are grateful to the directors of Amin Hayat Memorial Trust and hospital and Punjab institute of Cardiology, who provided all the facilities to collect samples and relevant record about hypertensive patients visiting the hospitals.

\section{Disclosure}

The authors have no conflicts of interest in this work.

\section{References}

1. Kearney PM, Whelton M, Reynolds K, Muntner P, Whelton PK, He J. Global burden of hypertension: analysis of worldwide data. Lancet 2005;365:217-23.

2. Walker AR, Walker BF, Segal I. Some puzzling situations in the onset, occurrence and future of coronary heart disease in developed and developing populations particularly in sub-Saharan Africa. J R Soc Promot Health 2004;124:40-6, 
3. Yusuf S, Reddy S, Ounpuu, S, Anand, S. Global burden of cardiovascular diseases. Part II: variations in cardiovascular disease by specific ethnic groups and geographic regions and prevention strategies. Circulation 2001;104:2855-64.

4. Cooper RS, Amoah AG, Mensah GA. High blood pressure: the foundation for epidemic Cardiovascular Disease in African populations. Ethn Dis 2003;13:S49-S52.

5. Kokkinos P, Panagiotakosand DB, Polychronopouls, E. Dietary influences on blood pressure: the effect of Mediterranean diet on the prevalence of hypertension. J Clin Hypertens 2007;7:165-72.

6. Appel LF, Moore TJ, Obarzanek E, Vollmer WM, Svetkey LP, Sacks EM, et al. A clinical trial of the effects of dietary patterns on blood pressure. DASH Collaborative Research Group N Engl Med J 1997;336:1117-24.

7. Pakistan Medical Research Council. National Health Survey 1990-1994: Health profile of people of Pakistan. Islamabad: Pakistan Medical Research Council,1998.

8. Khan A, Haq FU, Pervez MB, Saleheen D, Frossard PM, Ishaq M, et al. Anthropometric correlates of blood pressure in normotensive Pakistani subjects. Int J Cardiol 2008;124:25962.

9. Dhiman RK, Duseja A, Chawla Y. Asians need different criteria for defining overweight and obesity. Arch Intern Med 2005;165:1069-70.

10. Cooper R, Rotimi C, Ataman S, Mc Gee D, Osotimehin B, Kadiri S, et al. The prevalence of hypertension in seven populations of West African origin. Am J Public Health 1997;87:160-8.

11. Jia WP, Xiang KS, Chen L, Lu JX, Wu YM. Epidemiological study on obesity and its comorbidities in urban Chinese older than 20 years of age in Shanghai, China. ObesRev 2002;3: 157-65.

12. National Center for Health Statistics. NHANES III Anthropometric Procedures Video. Washington, DC: U.S. Government Printing Office. 1996.

13. Molarius A, Seidell JC, Sans S Tuomilehto J. Kuulasmaa K. Waist and hip circumferences, and waist-hip ratio in 19 populations of the WHO MONICA Project. Int J Obes Relat Metab Disord 1999;23:116-25.

14. James PT. Obesity: The worldwide epidemic. Clin Dermatol 2004;22:276-80.

15. Chobanian AV, Bakris GL and Black HR. et al. The Seventh Report of the Joint National Committee on Prevention, Detection, Evaluation, and Treatment of High Blood Pressure: The JNC 7 Report. JAMA 2003; 289:2560-71.

16. Hajjar I, Kotchen TA. Trends in prevalence, awareness, treatment, and control of hypertension in the United States, 1988-2000. JAMA 2003;290:199-206.

17. Massie BM, Mcphee SJ. Systemic Hypertension. In: Current Medical Diagnosis and Treatment. Eds, Tierney LMJr, Mcphee SJ, Papadakis MA, USA: Lange 2005;404-29.
18. Sullivan J. Gender differences in hypertension. $27^{\text {th }}$ Annual Scientific Meeting of the American Society of Hypertension, 2012.

19. Onal Ae, Erbil S, Ozel S, Fujishima M. The prevalence of and risk factors for hypertension in adults living in Istanbul. Blood Press 2004;13:31 -6 .

20. Velazquez MO, Rosas PM, Lara EA, Pastelin HG, Attie F, Tapia CR, et al. Arterial hypertension in Mexico: results of the National Health Survey 2000. Arch Cardiol Mex 2002;72:71-84.

21. World Health Organization. Obesity: Preventing and managing the global epidemic. Report of a WHO consultation on Obesity. Geneva, WHO, 1998.

22. Prentice AM, Jebb SA. Obesity in Britain: gluttony or sloth? BMJ 1995;311:437-9.

23. Hodge AM, Dowse GK, Gareeboo H, Tuomilehto J, Alberti KG, Zimmet PZ. Incidence, increasing prevalence, and predictors of change in obesity and fat distribution over 5 years in the rapidly developing population of Mauritius. Int $J$ Obes Relat Metab Disord 1996;20:137-46.

24. Popkin BM, Paeratakul S, Ge K, Zhai F. Body weight patterns among the Chinese: results from the 1989 and 1991 China Health and Nutrition Surveys. Am J Public Health 1995;85:690-4

25. Sakurai M, Miura K, Takamura T, Ota T, Ishizaki M, Morikawa Y, et al. Gender difference in the association between anthropometric Indices of Obesity and blood pressure in Japanese. Hypertens Res 2006;29:75-80.

26. Akhtar MS, Ansar SM, Abbas N, Ahmad N. Study of blood pressure patterns versus serum lipid parameters in obese Human subjects. Med $J$ Islamic World Acad Sci 2006;16:5-10.

27. Kotani K, Tokunaga K, Fujioka S, Kobatake T, Keno Y, Yoshida S, et al. Sexual dimorphism of age-related changes in whole-body fat distribution in the obese. Int J Obes Relat Metab Disord 1994;18: 207-12.

28. Flynn MA, Molph GB, Baker AS, Krause G. Aging in humans: a continuous 20 years study of physiologic and dietary parameters. $\mathrm{J} \mathrm{Am}$ Coll Nutr 1992;11: 660-72.

29. Lai SW, Li TC, Lin CC, Tan CK, Ng KC, Lai $\mathrm{MM}$, et al. Hypertension and its related factors in Taiwanese elderly people. Yale $J$ Biol Med 2001;74:89-94.

30. Syed S, Hingorjo MR, Charania A, Qureshi MA. Anthropometric and metabolic indicators in hypertensive patients. J Coll Physicians Surg Pak 2009; 19:421-7.

31. Nooritajer M, Rafiee S, Ravandi A, Mohamaei, F. Realtionship between hypertension and body mass index in the workers of Vitana factory. Euro $J$ Scien Res 2006;13:158-64.

32. Wilsgaard T, Schirmer H, Arnesen E. Impact of body weight on blood pressure with a focus on sex differences. Arch Intern Med 2000;160:284753. 